\title{
SiM
}

\section{Integrating a Rangeland Health Assessment With Successional Management}

\section{A Synergistic Approach to EBIPM}

\author{
By Edward A. Vasquez, Roger L. Sheley, Jeremy J. James, Tony J. Svejcar, \\ and Mike L. Pellant
}

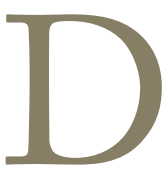
esigning restoration strategies based on successional management requires an initial assessment of the functional status of ecological attributes across a management unit. Seriously damaged rangelands may not have the capacity for self-repair and often experience continued degradation. ${ }^{1}$ Over the past 20 years, there has been a concentrated effort to develop a practical and effective protocol for assessing the status of rangeland health and managing vegetation change in heavily degraded rangelands. In the mid-1990s, a US National Research Council panel and a Society for Range Management task group advocated the use of early warning indicators to assess soil stability, water cycle, energy flow, nutrient cycling, and the resilience and resistance of plant communities to change following disturbances. Currently a widely adopted rangeland health assessment tool in the United States is "Interpreting Indicators of Rangeland Health, version 4," described by Pyke et al. ${ }^{2}$ and Pellant et al. ${ }^{3}$ This qualitative rangeland health assessment protocol provides early warnings of altered ecological processes and can help identify potential candidate locations for establishing quantitative monitoring plots for long-term trend studies.

Major advances of successional management models have also been developed, tested, and refined over the last two decades. ${ }^{4-6}$ Successional management is based on the causes of vegetation dynamics and represents a shift toward strategies that use ecological processes and mechanisms for restoration decision making. Integrating the rangeland health assessment with successional management enhances the usefulness of both systems and provides a holistic approach to the decision-making process. Our overall goal with this article is to provide a description of how rangeland health assessment and successional management can be integrated to form a holistic Ecologically Based Invasive Plant Management (EBIPM) framework. We describe the rangeland health assessment protocol and successional management framework including a detailed "hypothetical example" of integrating this holistic framework. We conclude by briefly discussing how this holistic framework can improve land managers' ability to effectively manage invasive plants.

\section{Rangeland Health Assessment}

Rangeland health assessment uses the ecological site concept in combination with professional knowledge of soils and vegetation properties to evaluate the biological and physical components of a site relative to a reference state. The reference state is where the functional capacities represented by three attributes (soil/site stability, hydrologic function, and biotic integrity) are functioning within a normal range of variation under a natural disturbance regime. Therefore, evaluation areas should include the natural variability of the ecological sites of concern within a management unit, or they should be a representative subsample of strata across the landscape. ${ }^{2}$

Once the soils and ecological site(s) occurring in the evaluation area have been identified, reference sheets provided in ecological site descriptions are then used to identify the natural range of variability of indicators in the reference state. Obtaining or developing an ecological site reference sheet facilitates consistent application of the process throughout the ecological site or management unit by integrating all available sources of data and knowledge to generate a description of the natural range of expected variation for each indicator of rangeland health. If a reference sheet is not available, one must be developed in order to conduct a site assessment. Reference sheets for ecological sites should be updated by reviewing available literature and unpublished data, and by consulting with a group of local experts. Rangeland health assessments should be conducted by an interdisciplinary team that evaluates the relative departure of the three attributes from what is expected for a particular ecological site. 


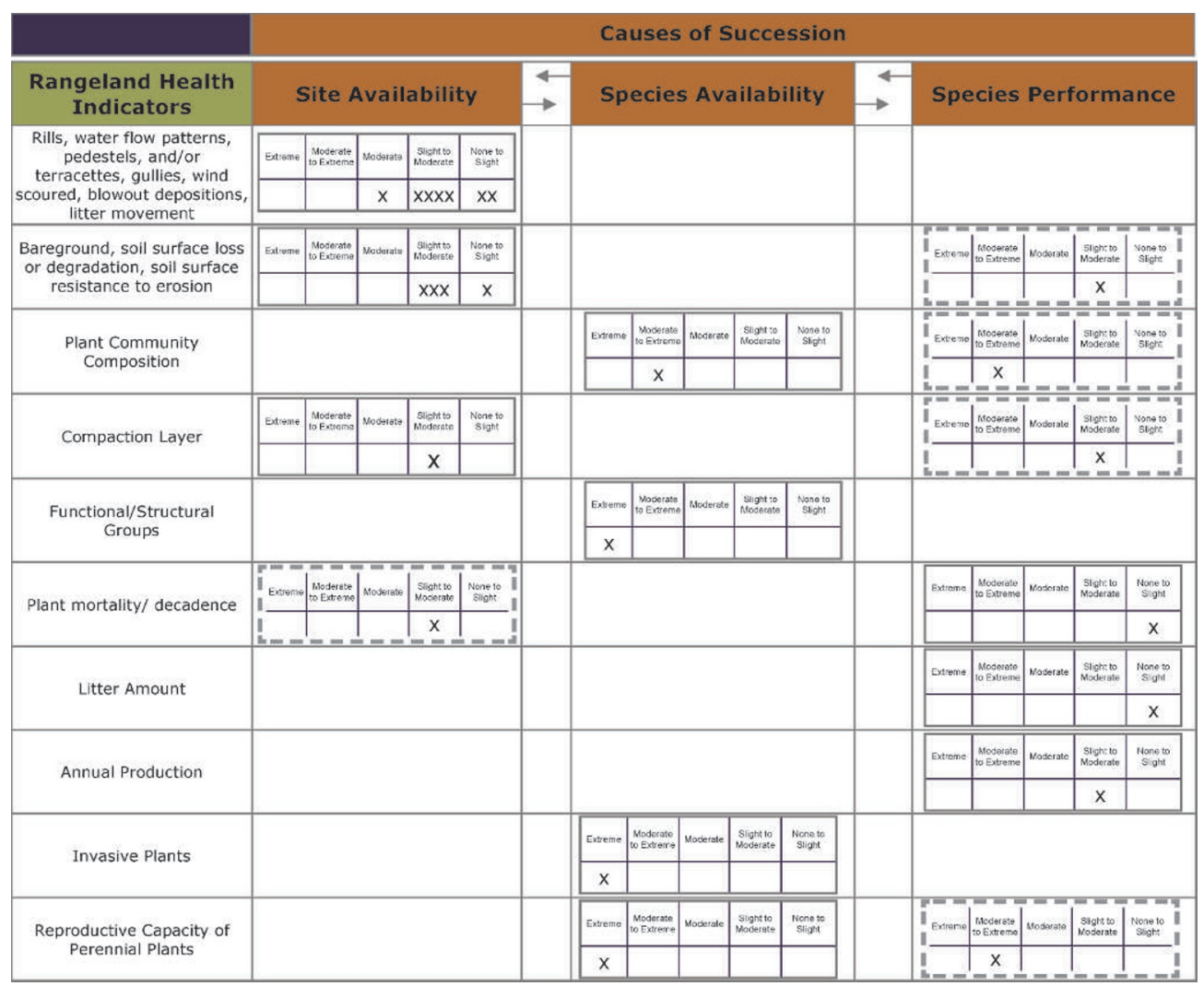

Figure 1. Summary table of rating for indicators organized by the primary (solid box) and secondary (dashed box) causes of succession. Boxes marked with an $\mathrm{X}$ are associated with the hypothetical example discussed in this paper and in Sheley et al. ${ }^{9}$

\section{Successional Management Framework}

Pickett et al. ${ }^{4}$ and Sheley et al. ${ }^{5,6}$ have developed a conceptual model for successional management, which has been tested over the past two decades as a framework for restoration of degraded weed-infested rangelands. EBIPM has combined the successional theory describing causes of succession with a management framework that modifies factors underlying the ecological processes and drivers of succession. ${ }^{5}$ EBIPM has evolved to a hierarchical model emphasizing rangeland health assessment, causes of succession, processes influencing these causes, planning and management guidelines based on ecological principles, and adaptive management (see Sheley and Smith, "Ecologically Based Invasive Plant Management: Step by Step," this issue). ${ }^{6}$ In this model, management tools and strategies based on ecological principles are designed to focus on specific ecological processes that affect one or more of the three causes of succession. This links manager-imposed treatments with the ecological processes driving plant community dynamics. Based on this successional model, a range of tools can be identified, developed, and strategically imposed by resource managers to direct ecosystem trajectories. Specifically, this model provides a way for managers to understand how to apply the appropriate combination of tools and strategies to address the underlying cause of invasion rather than perpetually controlling invasive plant abundance over the long term.

\section{Integrating Rangeland Health Assessment With Successional Management}

The diversity of rangeland ecosystems and specific management objectives ensures that no "silver bullet" approach can possibly have universal application, particularly where invasive species are expanding into indigenous ecosystems. Identification of the causes of successional dynamics is an initial step toward identifying potential restoration strategies for facilitating desired change within the management unit. The rangeland health assessment provides critical ecological information needed for successional management by identifying the status of rangeland health indicators and attributes and can be used to assist managers in identifying ecological processes in need of restoration. ${ }^{9}$

To inform the successional management model, Sheley et al. ${ }^{9}$ used the most current ecological literature to recategorize the 17 indicators from the rangeland health assessment into the three general causes of succession (Fig. 1). Because many indicators are related to more than a single cause of succession, the primary and secondary causes of succession have been identified for each indicator or group of indicators. ${ }^{9}$ Rangeland health indicators were also combined that have similar effects on individual causes of succession. For example, rills, water-flow patterns, pedestals and/or terracettes, gullies, wind-scoured soils, blowout depositions, and litter movement are combined into a single category as- 
sociated with site availability because the proportion of bare ground and disturbance intensity is often positively associated with site availability. Similarly, bare-ground, soil surface loss and resistance were also combined into a single category. Plant community composition has been modified from the original indicator in the rangeland health assessment that relates changes in composition and distribution to infiltration and runoff. A summary version for the group of these combined indicators can be used in these evaluations. Once the rangeland health indicators have been rated, that information, combined with knowledge of whether the indicator is primarily or secondarily associated with a cause, can be used to provide an indication of the relative importance of each cause in directing succession at the ecological site level. This information is central to using the successional management model because it provides the initial link to identifying the ecological processes in need of repair for successful restoration treatments. ${ }^{6,9,10}$

Rangeland health assessment is predominately qualitative, but most indicators can be measured quantitatively. 2,3 The magnitude and degree to which they indicate that a particular cause is driving successional dynamics is extremely variable. Consequently we suggest resource managers consider this assessment as a relative indication of the primary causes driving succession. As the number of indicators in the extreme and moderate to extreme rating increases, it is reasonable to suspect that those causes are driving succession because they deviate far from the expected conditions provided in the reference sheet. Additionally, this evaluation should be used with other information, such as site history, observations, and land managers' experience working on the management unit. This information should be used to focus on an initial starting point in the identification of ecological processes that appear in need of restoration. By using the EBIPM successional management framework, managers can methodically work their way through a thought process that can lead to the development and implementation of a truly ecologically based management system.

\section{A Synergistic Approach to Rangeland Health Assessment and Successional Management}

We applied the results of a "hypothetical example" of a completed rangeland health evaluation summary worksheet ${ }^{9}$ to the assessment of causes of succession worksheet (Fig. 1).6,9 We assume in this hypothetical example that the evaluation area was large enough to accurately evaluate all indicators and was at least $1 / 2$ to 2 acre in size for the ecological site occurring in the evaluation area. ${ }^{3}$ Following a rangeland health assessment, the relative departure of each indicator from what is expected for this ecological site were incorporated into Figure 1. Using the assessment information in this approach, we determined that the associated primary and secondary indicators were found to deviate only slightly to moderately from the reference sheet found in the ecological site description, which suggests that site availability is not a primary cause of degradation in this system. Although soil compaction can become an issue with repeated impacts on or disturbances of the soil surface, limitations on plant growth, water infiltration, and nutrient cycling processes appear to be within the normal variation of the ecological site or management unit. The deviation of plant mortality/decadence of desired vegetation associated with species performance is none to slight, suggesting the site still has a healthy mixture of plants compared to the dead or decadent component of the plant community relative to the sites' potential and climatic conditions. However, species availability of both desirable and undesirable invasive plants deviates moderately to extremely. Invasive plant species that have propagules present at a site or can get them there are likely to expand their population densities following continued disturbance. Changes in plant community composition and distribution of species can enhance or reduce the ability of the site to capture and store precipitation. Additionally, species performance tended to deviate moderately to extremely. Species performance is probably the broadest and most variable of the three causes of plant community change. There are numerous ways in which the performance of species can be affected, each with different processes and modifying factors affecting species performance as contained in the successional management framework. From this assessment, it appears that the primary causes of degradation are related to those processes associated with species availability and species performance. Management efforts aimed at modifying these processes may provide the most positive response in directing the plant community on a desired trajectory. This may involve manipulating site availability if necessary to establish desired species because they are low in abundance. However, site availability cannot guarantee successful restoration because dispersal of propagules appears to be a major limiting factor of reestablishment of a healthy functioning ecosystem.

\section{Management Implications}

EBIPM can be achieved only if the underlying ecological cause of degradation is altered to favor successional dynamics toward a desired plant community and, ultimately, their associated interactions with other essential components of ecosystem goods and services. Because the sustainability of rangelands depends on stable soils relative to site potential, functional hydrologic processes, and the integrity of nutrient cycles and energy flows, it is important to focus on those processes. Integrating the rangeland health assessment with successional management improves our ability to implement EBIPM successfully by associating assessment with ecological processes in need of repair. The holistic nature of integrating rangeland assessment with successional management as a first step provides the thought process and direction to successfully shift vegetation dynamics toward a favorable direction. Recognizing that invasion is not a discrete event, but a continuous process is fundamentally necessary if individual rangeland professionals are to visualize how to combat this growing threat. A synergistic approach to EBIPM will help 
resource managers by avoiding unnecessary management inputs and has the additional advantage of minimizing unintended negative impacts on ecological processes.

\section{Acknowledgments}

The authors would like to thank the USDA-ARS for sponsoring this special issue of Rangelands. In addition, we would like to express our appreciation to Brenda Smith and Ryan Steineckert for their dedication to the EBIPM area-wide project.

\section{References}

1. Whisenant, S. G. 1999. Repairing damaged wildlands: a process oriented, landscape-scale approach. New York, NY, USA: Cambridge University Press. 312 p.

2. Pyke, D. A., J. E. Herrick, P. Shaver, and M. Pellant. 2002. Rangeland health attributes and indicators for qualitative assessment. Journal of Range Management 55:584-597.

3. Pellant, M., P. Shaver, D. A. Pyke, and J. E. Herrick. 2005. Interpreting indicators of rangeland health: version 4. Denver, CO, USA: US Department of the Interior, Bureau of Land Management, National Science and Technology Center. Technical Reference 1734-6. 122 p.

4. Pickett, S. T. A., S. L. Collins, and J. J. Armesto. 1987. Model, mechanisms, and pathways of succession. Botanical Review 53:335-371.

5. Sheley, R. L., T. J. Svejcar, and B. D. Maxwell. 1996. A theoretical framework for developing successional weed management strategies on rangeland. Weed Technology 10:766-773.
6. Sheley, R. L., J. J. James, B. Smith, and E. A. Vasquez. 2010. Applying ecologically-based invasive-plant management. Rangeland Ecology E Management 63:605-613.

7. Sheley, R. L., J. M. Mangold, And J. L. Anderson. 2006. Potential for successional theory to guide restoration of invasive plant-dominated rangelands. Ecological Monographs 76:365-379.

8. Sheley, R. L., J. J. James, and E. C. Bard. 2009. Augmentative restoration: repairing damaged ecological processes during restoration of heterogeneous environments. Invasive Plant Science and Management 2:10-21.

9. Sheley, R. L., J. J. James, E. A. Vasquez, and T. J. Svejcar. 2011. Using rangeland health assessment to inform successional management. Invasive Plant Science and Management 4:356-367.

10. James, J. J., B. S. Smith, E. Vasquez, And R. L. Sheley. 2010. Principles for ecologically-based invasive plant management. Invasive Plant Science and Management 3:229-239.

Authors are Visiting Faculty, Forestry \& Wildland Resources Dept, Humboldt State University, Arcata, CA 95521, USA, eav150@humboldt.edu (Vasquez); Ecologist (Sheley) and Research Leader (Svejcar), USDA-ARS Eastern Oregon Agricultural Research Center, Burns, OR 97720, USA; Director and Extension Rangeland Specialist, UC Sierra Foothill Research and Extension Center, Browns Valley, CA 95918, USA (James); and Ecologist, Bureau of Land Management, Nevada State Office, Boise, ID 83709, USA (Pellant). 